This item was submitted to Loughborough's Research Repository by the author.

Items in Figshare are protected by copyright, with all rights reserved, unless otherwise indicated.

\title{
Low frequency lateral acceleration and subjective ratings of acceleration intensity and driving confidence in production cars
}

\section{PLEASE CITE THE PUBLISHED VERSION}

http://dx.doi.org/10.1260/0263-0923.23.4.221

\section{PUBLISHER}

(C) Multi-Science Publishing

\section{VERSION}

VoR (Version of Record)

\section{PUBLISHER STATEMENT}

This work is made available according to the conditions of the Creative Commons Attribution-NonCommercialNoDerivatives 4.0 International (CC BY-NC-ND 4.0) licence. Full details of this licence are available at: https://creativecommons.org/licenses/by-nc-nd/4.0/

\section{LICENCE}

CC BY-NC-ND 4.0

\section{REPOSITORY RECORD}

Mansfield, Neil J., and Elinor Whiting-Lewis. 2019. "Low Frequency Lateral Acceleration and Subjective Ratings of Acceleration Intensity and Driving Confidence in Production Cars". figshare. https://hdl.handle.net/2134/17326. 
Low Frequency Lateral Acceleration and Subjective Ratings of Acceleration Intensity and Driving Confidence in Production Cars

by

Neil J Mansfield and Elinor Whiting-Lewis

reprinted from

Journal of

LOW FREQUENCY

NOISE, VIBRATION

AND ACTIVE CONTROL

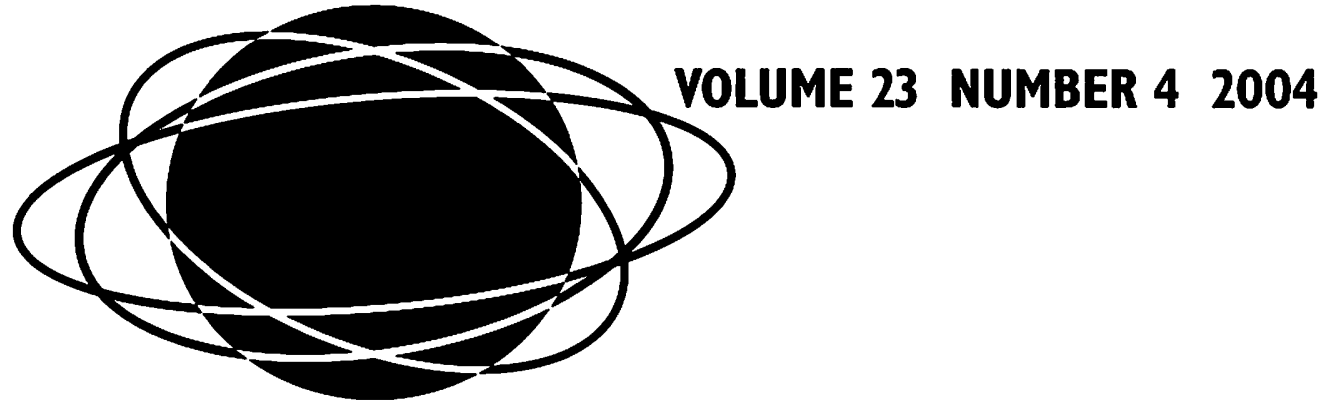




\title{
Low Frequency Lateral Acceleration and Subjective Ratings of Acceleration Intensity and Driving Confidence in Production Cars
}

\author{
Neil J Mansfield and Elinor Whiting-Lewis \\ Department of Human Sciences \\ Loughborough University \\ Loughborough \\ Leicestershire \\ LEII 3TU \\ United Kingdom \\ n.j.mansfield@iboro.ac.uk
}

Received 14 September 2004

\begin{abstract}
SUMMARY
There are few studies in the literature that relate subjective ratings to objective measures of low frequency lateral acceleration such as might be experienced whist cornering in a car. This paper reports a study where 1203 subjects drove two different cars ('sport' and 'comfort') on two different lateral acceleration trials. Objective measures of acceleration were taken, in addition to ratings of lateral acceleration intensity and confidence. It is shown that there was little difference between the peak lateral accelerations experienced in the two cars, although males chose to drive with greater lateral acceleration (i.e. at higher speed) than the females. Despite differences between the objective measures of acceleration being small, subjective data showed that the intensity of acceleration was rated higher for the comfort car than the sport car indicating that subjective ratings are context specific. Ratings of intensity were correlated with measures of peak acceleration for each car / trial combination. Drivers were more confident driving the sport car than the comfort car on the two trials. However, there was only a weak and inconsistent relationship between lateral acceleration and driving confidence. It is hypothesised that this is an example of risk homeostasis whereby drivers choose to moderate their speed (and therefore the lateral acceleration) in response to their confidence level that might be affected by a complex combination of factors.
\end{abstract}

\section{INTRODUCTION}

Car occupants are exposed to acceleration in a variety of forms. During steady driving in a straight line, vibration occurring at the steering wheel, pedals, floor and seat surface can be perceived by the driver (e.g. Giacomin et al., 2004; Haasnoot and Mansfield, 2002). Whilst accelerating and braking, low frequency acceleration also occurs in the fore-and-aft direction. Whilst cornering, low frequency lateral acceleration also occurs.

Most previous studies concerning human response to acceleration in cars have focused on the vibration experienced at the seat surface (e.g. Nakashima and Maeda, 2004; Chen et al., 2003; van Niekerk et al., 2003; Hassan and McManus, 2002; Mansfield et al., 2000). However, there is little in the current literature which investigates the objective and subjective responses of car drivers to the effects of solely lateral acceleration in 'normal' conditions (i.e. non-impact). Therefore standardised methodologies have not been developed for investigation of these issues.

It has been shown that as speed increases, non-professional drivers choose to reduce the lateral acceleration to which they are exposed. This means that drivers 
could corner at higher speeds than they feel safe to do if they are travelling quickly, but have a lower safety margin at slower speeds (Reymond et al., 2001). This effect can be illustrated by considering the fact that loads carried within vehicles tend to move more frequently whilst carrying out slow speed manoeuvres than whilst manoeuvring (e.g. changing lanes, turning corners) at higher speeds; the coefficient of friction between loads and the floor of vehicles does not depend on speed. Similarly, tyre squeal occurs more often at low speed than at high speed despite the saturation threshold of tyres (i.e. the limit of lateral grip) only changing slightly with speed. For most cars, slip will not occur until lateral accelerations exceed approximately 8 to $10 \mathrm{~ms}^{-2}$ (e.g. Reymond et al., 2001). Professional drivers can drive with lower safety margins and are capable of exceeding saturation thresholds at high and low speeds, where the car will start to slip. However, even for professional drivers, subjective responses to lateral acceleration are variable (Laurence et al., 2000) depending on what criteria are used to judge the vehicle.

There are no known studies investigating subjective opinions of driving confidence for non-professional drivers in comparison with objective measures of lateral acceleration. It is possible that if drivers are more confident with their vehicle, then they will choose to drive with greater lateral acceleration resulting in a monotonic relationship between confidence and the lateral acceleration; conversely, it is possible that drivers could choose to drive with a greater safety margin such that they maintain confidence in the ability of the vehicle to safely turn the comer resulting in an inverse or no relationship between confidence and lateral acceleration.

Likewise, there are no known studies investigating subjective opinions of acceleration intensity for non-professional drivers in comparison with objective measures of lateral acceleration. It is likely that subjective ratings of acceleration intensity will increase monotonically with acceleration intensity. However, it is possible that subjective ratings will be context specific such that ratings in one car (e.g. a sports car) will not be comparable to ratings in another car (e.g. a small budget car).

This paper reports a study where subjective ratings of lateral acceleration intensity and confidence were compared to objective measures of lateral acceleration measured in two different cars driving on a private road.

\section{METHODS}

\subsection{Test Circuit}

The lateral acceleration trials took place at Prestwold Hall racing circuit, Leicestershire, UK which had been recently resurfaced. Two lateral acceleration trials were completed for each driver/car combination. Trial 1 occurred on a smooth tarmac surface and comprised a section with alternating turns followed by a short straight. Trial 2 occurred on a smooth tarmac surface and comprised a tight right hand turn, a $400 \mathrm{~m}$ straight which was followed by a moderate left hand turn and a $150 \mathrm{~m}$ straight (Figure 1).

\subsection{Test Vehicles}

All trials were completed by participants driving two different Ford Mondeo cars (July 2003 models). The cars were classed as 'comfort' and 'sport' reflecting the emphasis of each model, although both sets of cars were designed to feel 'comfortable' and 'sporty' by the manufacturer.

Five 'comfort' and five 'sport' cars were used for the trials, although each driver only drove one of each type. Tyres were replaced when necessary.

\subsection{Objective Measurements}

Lateral acceleration of the cars was measured using Race Technology AC22 Automotive Performance Meters. The meters were firmly fixed to the dashboards of each of the cars and were configured to measure the maximum cornering acceleration. The meters sampled the lateral acceleration at $100 \mathrm{~Hz}$ with a resolution of $0.01 \mathrm{~g}$ and a range of $+/-2 \mathrm{~g}$. Lateral acceleration was measured for each driver in each car for each of the lateral acceleration trials and could therefore be associated with individual subjective responses. 


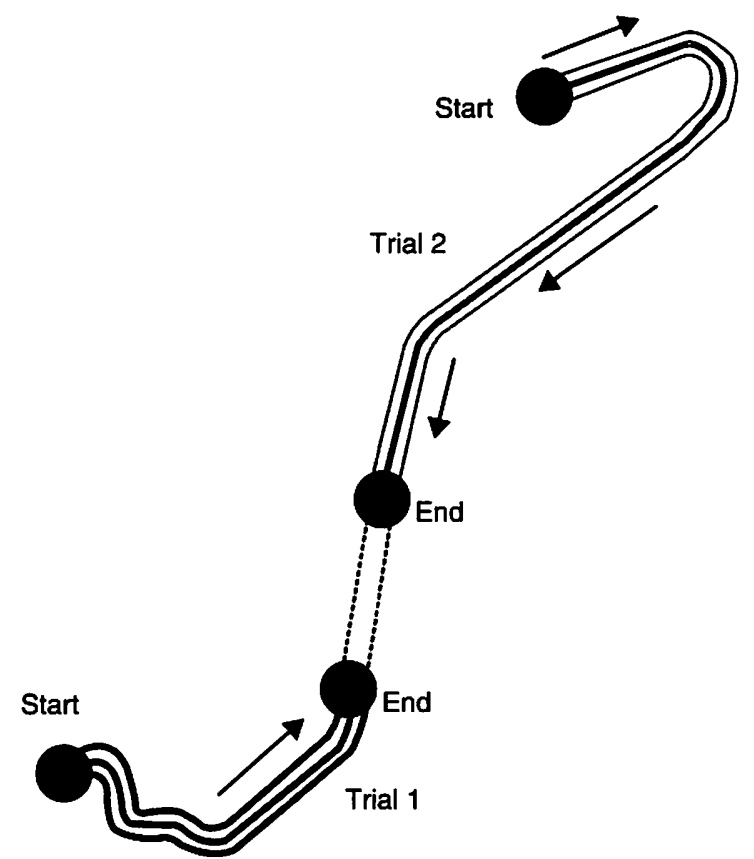

Figure I Map of the part of Prestwold Hall circuit that was used for the lateral acceleration trials

\subsection{Subjective Measurements}

All data was obtained using a questionnaire that was administered by the instructor in the car but answered by the driver. The first section of the questionnaire was completed before the driver commenced their trial. It obtained demographic data and established the condition of the circuit (although weather conditions remained dry throughout the duration of the trial).

Subsequent sections of the questionnaire sought data on the maximum lateral acceleration along with the participants' subjective ratings of lateral acceleration intensity and their level of confidence driving the car whilst driving the lateral acceleration trials. Intensity was rated using a seven point Likert scale for each of the trials, 1 being 'not at all intense' to 7 being 'extremely intense'. Driver confidence during the test was also rated using a seven point Likert scale, with 1 being 'not at all confident' to 7 being 'extremely confident'.

Each driver therefore gave subjective ratings of confidence and intensity for both cars driving both trials, resulting in eight data points per driver.

\subsection{Participants}

1284 individuals participated in the study. Any questionnaires with missing data points were removed from the analysis, leaving 1203 complete data sets. $87 \%$ of these participants were male and $13 \%$ were female. Demographic data for the participants are collated in Table I. Statures and standard deviations are typical of those that would be expected of the general population (Pheasant, 1998).

Table I. Demographic data for the 1203 participants that completed the trials

\begin{tabular}{lccccc} 
& & \multicolumn{2}{c}{ Age } & \multicolumn{2}{c}{ Stature } \\
\cline { 3 - 6 } & Number & Mean & s.d. & Mean & s.d. \\
\hline Males & 1052 & 35.5 & 11.2 & 179.4 & 6.9 \\
Females & 151 & 31.2 & 8.1 & 164.8 & 7.0 \\
All & 1203 & 34.9 & 11.0 & 177.6 & 8.4 \\
\hline
\end{tabular}




\section{EXPERIMENTAL PROCEDURE}

Participants were transported to the trials by bus in groups of up to 20 people. Whilst on the buses, the participants watched a short training video describing the trials that they were about to participate in.

Each car was occupied by two participants plus an instructor. The instructor assumed the driving position and drove the participants around the circuit once, to familiarise the participants with the route. They then took demographic information and reiterated the explanation of the tests. In addition to their role as instructors, they also asked the questions and recorded the responses during the tests.

All ten of the cars formed a convoy and followed each other to perform each of the tests in turn to ensure safety of the movement of vehicles around the site.

The first driving trial was the lateral acceleration 1 trial. For this the acceleration meter was reset and the participant as asked to drive the lateral acceleration 1 circuit as quickly as possible, but safely. The car was then brought to a halt and the maximum acceleration stored by the acceleration meter was recorded along with the participants subjective ratings of lateral acceleration intensity and their level of confidence driving the car. The car was then driven to the start of the lateral acceleration 2 trial, following the circuit in the reverse direction. The lateral acceleration 2 trial was then completed using a similar procedure to that for the lateral acceleration 1 trial.

The speeds obtained during the lateral acceleration trials varied between participants but were higher than would be usually encountered when driving around similar bends in normal driving on public roads. Speeds obtained on the straight in the lateral acceleration 2 trial often substantially exceeded the UK national speed limit. However, these speeds were not logged as they were not directly relevant to the main purpose of the investigation.

Once the tests were completed the cars were returned to the beginning of the circuit, the participants swapped places and the tests were competed again. After both participants had completed the first car, they then swapped with another group to test the second car.

Although the car type was balanced in order of presentation, it was not possible to balance the order of the trials, due to safety concerns with a fleet of cars driving a circuit at high speed.

\section{RESULTS}

\section{I Peak Lateral Acceleration}

The peak lateral acceleration was measured for each participant in each of the trials. Peak accelerations were similar between trials and cars for all tests (Figure 2, Table II). The highest peak lateral acceleration values obtained during the trials were

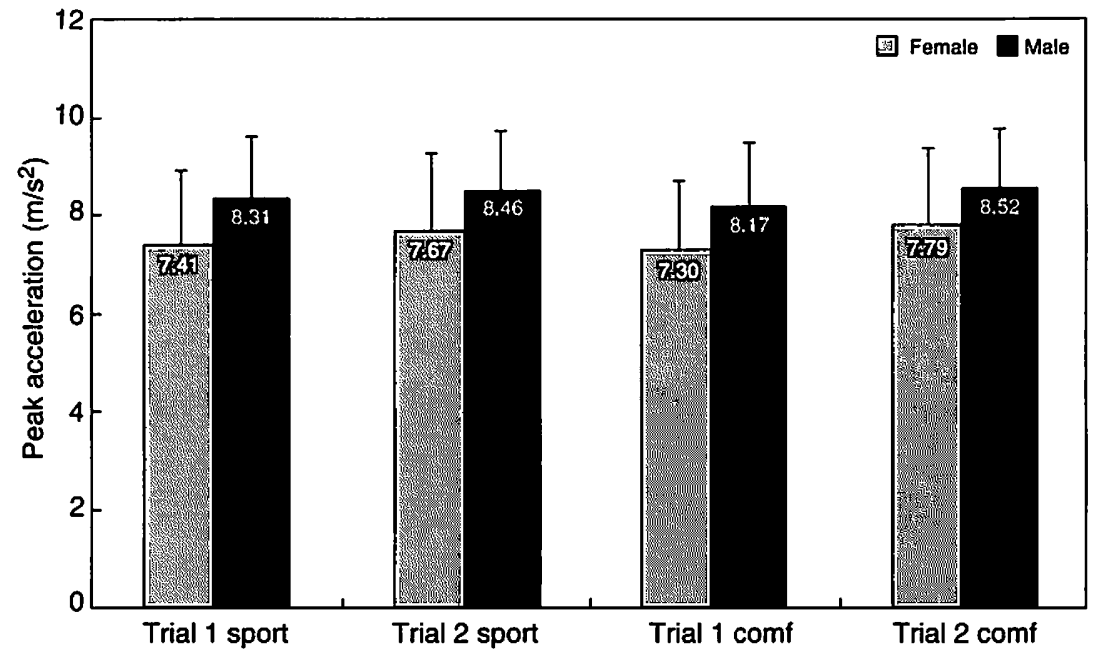

Figure 2 Mean peak lateral acceleration for the two cars measured for the two trials separated into data for males and females. Error bars correspond to standard deviations 
Table II. Lateral accelerations measured for subjects driving two different cars on two different circuits. Data report the mean and standard deviation of the peak accelerations in $\mathrm{m} / \mathrm{s}^{\mathbf{2}}$

\begin{tabular}{lccccccc} 
& & \multicolumn{2}{c}{ All $(\mathrm{n}=1203)$} & \multicolumn{2}{c}{ Males $(\mathrm{n}=1052)$} & \multicolumn{2}{c}{ Females $(\mathrm{n}=151)$} \\
\cline { 3 - 8 } Car & Trial & Mean & s.d. & Mean & s.d. & Mean & s.d. \\
\hline \multirow{2}{*}{ Sport } & 1 & 8.20 & 1.36 & 8.31 & 1.30 & 7.41 & 1.50 \\
& 2 & 8.36 & 1.33 & 8.46 & 1.25 & 7.67 & 1.60 \\
\multirow{3}{*}{ Comfort } & 1 & 8.06 & 1.35 & 8.17 & 1.30 & 7.30 & 1.41 \\
& 2 & 8.43 & 1.31 & 8.52 & 1.24 & 7.79 & 1.58 \\
\hline
\end{tabular}

Table III. Intensity assessed by subjects driving two different cars on two different trials ( $I=$ not at all intense, $7=$ extremely intense)

\begin{tabular}{lccccccc} 
& & \multicolumn{2}{c}{ All $(n=1203)$} & \multicolumn{2}{c}{ Males $(n=1052)$} & \multicolumn{2}{c}{ Females $(n=151)$} \\
\cline { 3 - 8 } Car & Trial & Mean & s.d. & Mean & s.d. & Mean & s.d. \\
\hline \multirow{2}{*}{ Sport } & 1 & 3.12 & 1.63 & 3.07 & 1.62 & 3.48 & 1.70 \\
& 2 & 3.15 & 1.81 & 3.09 & 1.81 & 3.53 & 1.80 \\
\multirow{3}{*}{ Comfort } & 1 & 3.52 & 1.36 & 3.50 & 1.36 & 3.69 & 1.37 \\
& 2 & 3.52 & 1.44 & 3.51 & 1.44 & 3.65 & 1.42 \\
\hline
\end{tabular}

11.38 and $11.48 \mathrm{~m} / \mathrm{s}^{2}$ for the sport car driving trials 1 and 2 respectively and were 12.95 and $11.67 \mathrm{~m} / \mathrm{s}^{2}$ for the comfort car driving trials 1 and 2 respectively. Only 14 of the participants exceeded $9.81 \mathrm{~m} / \mathrm{s}^{2}$ (i.e. a lateral-g of 1.0 ) for all of the trials, despite 356 (approximately 30\%) exceeding this value for at least one of the trials.

Although the differences between cars and between trials were small, statistical testing showed that the differences were significant $(\mathrm{p}<0.001)$. However, it should be noted that statistical testing (such as paired samples t-tests used here) loses some meaning when dealing with such large data sets. For example, if data are considered for the female subjects only (where the sample size is smaller and closer to the typical data sets that would be used with such statistical testing) then the differences between the cars are not significant.

Males reached greater peak lateral accelerations than females (independent samples $t$-test, $p<0.001$ ). The mean difference between the peak accelerations was $0.82 \mathrm{~m} / \mathrm{s}^{2}$.

\subsection{Subjective Ratings of Acceleration Intensity}

Each participant rated the intensity of the lateral acceleration whilst driving the two trials in the two cars. The ratings of intensity were not significantly different between the two trials $(p>0.05)$. However, the intensity was rated as greater for the comfort car than for the sport car. These differences were significant $(p<0.001)$. Females tended to judge the intensity in the cars higher than the males (Table III, Figure 3). However, the differences in the judgements were only significant for the judgements made of the sport car $(p<0.05)$.

\subsection{Subjective Ratings of Confidence}

Each participant rated their confidence whilst driving the two trials in the two cars. Ratings tended to be greater for the second trial and this difference was significant (Table IV). Participants were consistently more confident when driving the sport car than when driving the comfort car $(\mathrm{p}<0.001)$. Males were significantly more confident than the females when driving the sport $c a r(p<0.001$; Figure 4$)$. However the difference between the genders was not significant when driving the comfort $\operatorname{car}(\mathrm{p}>0.05)$. 


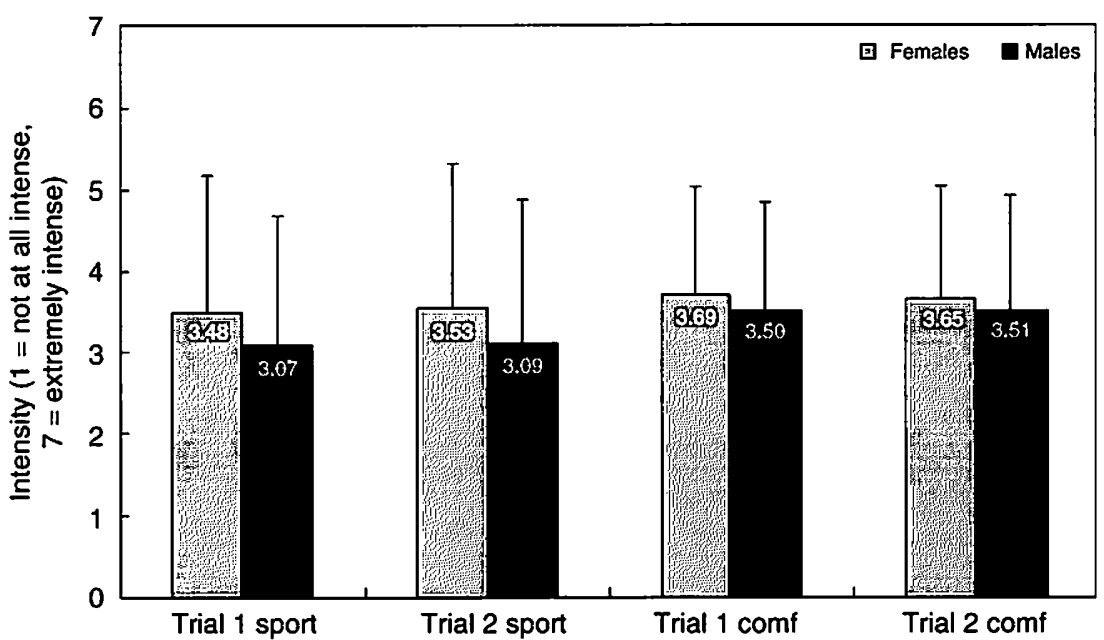

Figure 3 Mean ratings of lateral acceleration intensity measured for the two cars whilst driving the two trials, separated into data for males and females. Error bars correspond to standard deviations

Table IV. Ratings of confidence reported by subjects driving two different cars on two different lateral- $\mathrm{g}$ trials $(I=$ not at all confident, 7 = extremely confident)

\begin{tabular}{lccccccc} 
& & \multicolumn{2}{c}{ All $(n=1203)$} & \multicolumn{2}{c}{ Males $(n=1052)$} & \multicolumn{2}{c}{ Females $(n=151)$} \\
\cline { 3 - 8 } Car & Trial & Mean & s.d. & Mean & s.d. & Mean & s.d. \\
\hline \multirow{2}{*}{ Sport } & 1 & 6.00 & 0.97 & 6.05 & 0.93 & 5.64 & 1.17 \\
& 2 & 6.19 & 0.93 & 6.24 & 0.89 & 5.81 & 1.10 \\
Comfort & 1 & 5.21 & 1.11 & 5.23 & 1.12 & 5.10 & 1.03 \\
& 2 & 5.42 & 1.09 & 5.44 & 1.10 & 5.32 & 1.05 \\
\hline
\end{tabular}

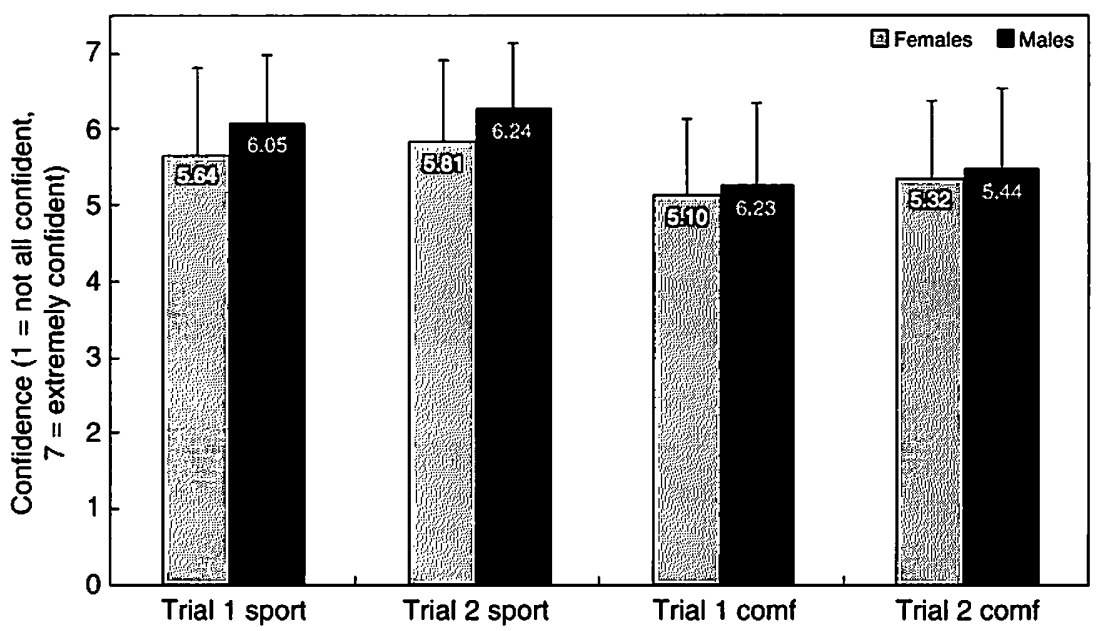

Figure 4 Mean ratings of lateral acceleration confidence measured for the two cars whilst driving the two trials, separated into data for males and females. Error bars correspond to standard deviations

\subsection{Correlation Between Subjective Ratings of Intensity and Objective Measures of Acceleration \\ There was a correlation between the ratings of intensity and the peak lateral accel- eration for all conditions ( $p<0.001$, Pearson). The correlation was stronger for the comfort car, although all correlations were significant. Slopes of the regression lines were slightly steeper for the lateral acceleration 2 trials than the lateral acceleration 1 trials and were slightly steeper for the comfort car (Figures 5 and 6).}



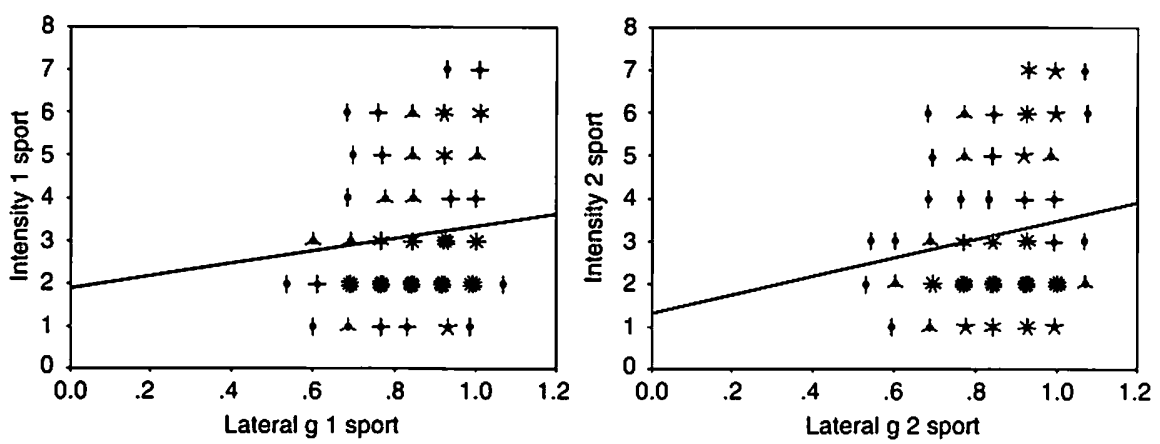

Figure $5 \quad$ Sunflower plots showing relationship between individual subjects' reported intensity and peak lateral acceleration for the sport car. Each petal represents 5 data points. Data points with less than 10 samples are not shown. (NB lateral accelerations are expressed as ' $\mathrm{g}$ ')
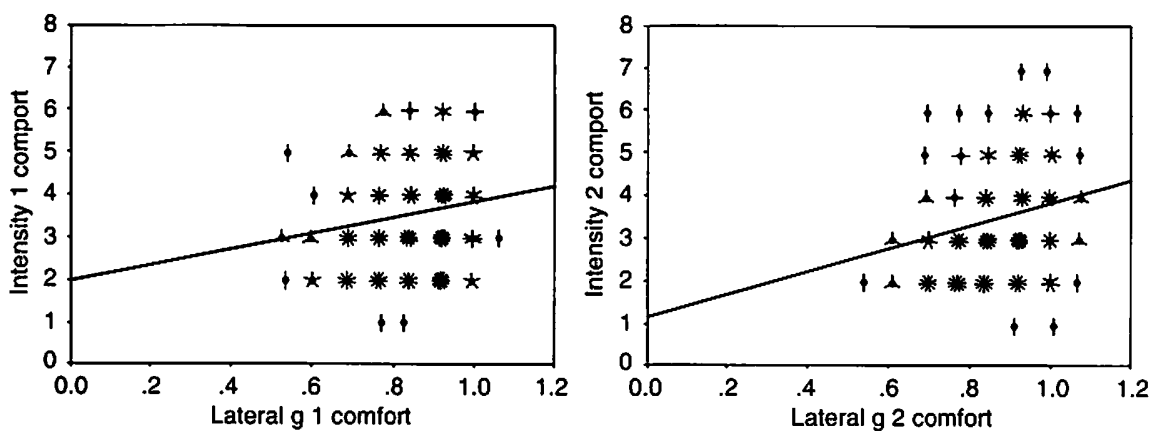

Figure 6

Sunflower plots showing relationship between individual subjects' reported intensity and peak lateral acceleration for the comfort car. Each petal represents 5 data points. Data points with less than 10 samples are not shown. (NB lateral accelerations are expressed as ' $\mathrm{g}$ ')

There was a correlation between the reports of confidence and the peak lateral acceleration for the sport car ( $p<0.001$, Pearson). There was no correlation for trial 2 acceleration and confidence for the comfort car $(p>0.05)$ and a weak correlation for trial 1 acceleration and confidence $(p<0.05)$. For the sport car, the correlation coefficient was positive indicating that drivers were slightly more confident when driving with a higher peak lateral acceleration, but the converse was true for the comfort car (Figures 7 and 8).

\section{DISCUSSION}

This study has been unique in the methods used to rate subjective responses to lateral acceleration whilst cornering in cars. Therefore, these data serve two purposes: firstly to evaluate subjective responses themselves and secondly to provide an initial methodology for evaluation of subjective responses to lateral acceleration.

Objective measurements of peak lateral acceleration showed that there was very little difference between the accelerations experienced in the cars. This is surprising as one would expect the sport version to corner more quickly than the comfort version. However, both cars are designed to perform well in terms of performance and so the differences between the cars remain small. It is interesting to note that the mean peak lateral acceleration obtained in the cars in approximately that considered to be the peak lateral acceleration before tyres lose grip (i.e. 8 to $10 \mathrm{~m} / \mathrm{s}^{2}$ ). Therefore, many drivers exceeded the lateral-grip capacity of the tyres. These data do not support the previous observations of Reymond et al., (2001) that drivers choose to drive with higher safety margins at high speed. However, drivers in the current study were aware that they were on a private racing circuit with no oncoming traffic and were accompanied by an instructor at all times. Therefore they might 

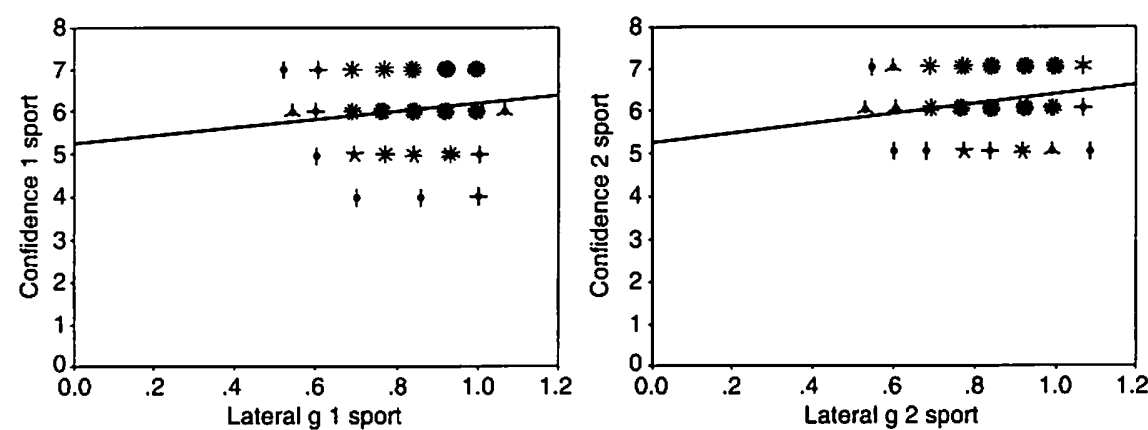

Figure 7 Sunflower plots showing relationship between individual subjects' reported confidence and peak lateral acceleration for the sport car. Each petal represents 5 data points. Data points with less than 10 samples are not shown. (NB lateral accelerations are expressed as ' $\mathrm{g}$ ')
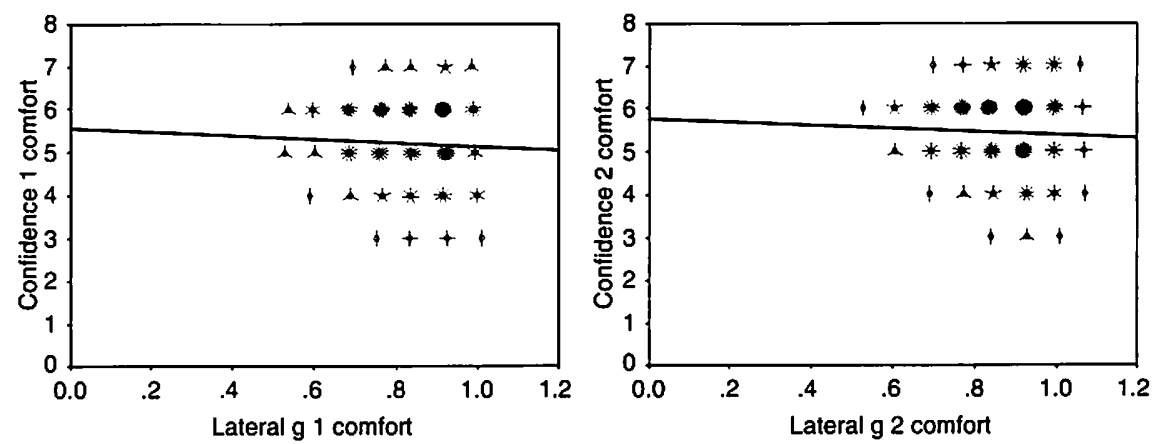

Figure 8

Sunflower plots showing relationship between individual subjects' reported confidence and peak lateral acceleration for the comfort car. Each petal represents 5 data points. Data points with less than 10 samples are not shown. (NB lateral accelerations are expressed as ' $g$ ')

have felt inherently safe as they would have assumed that the trials would not go ahead if they were considered unsafe.

Males drove the cars with greater lateral accelerations than the females (i.e. at higher speed through the corners). They also rated the intensity of the acceleration lower. However, males were more confident than the females. As the males were more confident with the cars, then it is logical that they would feel able to drive the cars more quickly through the corners.

Despite the two cars being driven with similar lateral accelerations, there was a difference in the subjective responses. Drivers felt that the lateral acceleration was more intense for the comfort car than the sport car, even though there was no consistent difference between the absolute acceleration magnitudes. This indicates that ratings of acceleration intensity are context specific such that ratings obtained in one vehicle are not necessarily comparable to those obtained in another vehicle.

Within each of the car-trial combinations there was a good correlation between the subjective ratings of intensity and the acceleration. This indicates that subjective ratings of lateral acceleration are reliable: i.e. if an individual considers that the acceleration was greater then it is likely that it was indeed greater.

Drivers felt less confident when driving the comfort car than when driving the sport car. It is possible that drivers' opinions were influenced by them knowing which type of car they were driving; however, it is also possible that the differences in responses are genuine. The comfort car had slightly more body roll when driving in the trials and this could have influenced ratings of confidence and intensity, as could the slightly different handling characteristics.

The low and inconsistent gradients between the ratings of confidence and lateral acceleration indicate that confidence may not be related to the acceleration per se, despite some of the relationships showing statistical significance. It is likely that 
drivers moderate driving behaviour depending on their confidence such that they will maintain a perceived level of risk whilst cornering (i.e. risk homeostasis: Janssen and Tenkink, 1988). Therefore, drivers' chosen driving speed whilst cornering may have been a function of their perception of their own driving ability and their own self-selected safety margin in addition to their perception of the performance of the car being driven. If this is the case, then drivers would select their speed, and therefore the lateral acceleration, based on their own safety margin. The results here might, therefore, simply indicate that the participants drove with similar levels of confidence but this was expressed as a wide range of speeds.

\section{CONCLUSIONS}

Objective measurements of lateral acceleration within two cars have been made whilst the cars drove two trials on a private road. There were no clear differences between the lateral accelerations measured for the two cars. Males reached higher lateral accelerations than females.

Subjective ratings of lateral acceleration intensity showed that lateral accelerations were considered more intense when driving in the comfort car than when in the sport car. Females rated the intensities slightly higher than the males.

Subjective ratings of confidence when driving the two lateral acceleration trials showed that participants were more confident when driving the sport car than when driving the comfort car. Males were slightly more confident than females.

Subjective ratings of lateral acceleration intensity were correlated to the objective measurements of lateral acceleration showing that drivers reliably discern the acceleration to which they and their cars are exposed.

Subjective ratings of confidence were not always correlated to the objective measurements of peak lateral acceleration, possibly due to risk homeostasis taking effect whereby drivers moderate their behaviour to maintain confidence whilst driving the vehicle.

\section{ACKNOWLEDGEMENTS}

This research was funded by Marketing International, Little Hadham, UK with support from Ford Motor Company Limited. The views expressed are those of the authors and not necessarily those of the sponsors.

\section{REFERENCES}

Chen JC, Chang WR, Shih TS, Chen CJ, Chang WP, Dennerlein JT, Ryan LM, and Christiani DC (2003) Predictors of whole-body vibration levels among urban taxi drivers. Ergonomics 46(11) 1075-90.

Giacomin J, Shayaa MS, Dormegnie E and Richard L (2004) Frequency weighting for the evaluation of steering wheel rotational vibration. International Journal of Industrial Ergonomics, 33(6) 527-541.

Haasnoot RA and Mansfield NJ (2002) Vibration magnitudes at the seat and steering wheel whilst driving over small bumps in cars. Paper presented at the 37th United Kingdom Conference on Human Responses to Vibration, held at Department of Human Sciences, Loughborough University, UK, 18-20 September 2002.

Hassan R and McManus (2002), Perception of low frequency vibrations by heavy vehicle drivers. Journal of Low Frequency Noise, Vibration and Active Control, 21(2).

Janssen WH and Tenkink E (1988) Considerations on speed selection and risk homeostasis in driving. Accident Analysis \& Prevention, 20(2) 137-142.

Laurence P, Basset M, Coutant P and Gissinger G (2000) Lateral vehicle behaviour: Comparison of subjective/objective assessment using the choquet integral. Vehicle System Dynamics 34(5). 
Mansfield NJ, Holmlund P and Lundström R (2000) Comparison of subjective responses to vibration and shock with standard analysis methods and absorbed power. Journal of Sound and Vibration, 230(3), 477-491.

Nakashima Y and Maeda S (2004) Effect of seat-back angle and accelerometer height at the seat-back on seat-back $x$ axis r.m.s. acceleration in field experiments according to the ISO2631-1 standard. Industrial Health 42, 65-74.

Pheasant S (1998) Bodyspace: anthropometry, ergonomics and the design of work, 2nd edition. London: Taylor \& Francis.

Reymond G, Kemeny A, Droulez J and Berthoz A (2001) Role of lateral acceleration in curve driving: Driver model and experiments on a real vehicle and a driving simulator. Human Factors 43(3) 483-495.

van Niekerk JL, Pielemeier WJ and Greenberg JA (2003) The use of seat effective amplitude transmissibility (SEAT) values to predict dynamic seat comfort. Journal of Sound and Vibration 260(5) 867-888. 